Bull. Mater. Sci., Vol. 5, No. 5, December 1983, pp.465-468. () Printed in India.

\title{
Stroboscopic studies of the elastic behaviour of some Indian timbers
}

\author{
M A KAREEM and D B SIRDESHMUKH \\ Department of Physics, Kakatiya University, Warangal 506009 , India \\ MS received 14 March 1983; revised 18 June 1983
}

\begin{abstract}
The dynamic Young's modulus has been determined for eleven Indian timbers using an electronic flash lamp stroboscope to measure the frequency of vibration of the timber bars. A linear relationship is observed between Young's modulus and the density of the timbers.
\end{abstract}

Keywords. Elastic properties; Young's modulus; noncrystalline materials; Indian timber; electronic flash lamp stroboscope

\section{Introduction}

Timber has come to be used not only for housing but also as a structural material for automobiles, aircraft and bridges. The elastic properties of a material play an important role in its structural use. The elastic properties of some European timbers are given by Hearmon (1953), of American timbers by Hansen (1960) and Russian timbers by Bazhenov (1961). Systematic studies on the elastic properties of Indian timbers are meagre. John and Lal (1964) determined the dynamic elastic modulus of 13 varieties of Indian timbers while Pradhan (1970) measured a single species (Bijasaal). In the present paper a systematic measurement of the dynamic Young's modulus (hereinafter represented by $E_{d}$ ) of about a dozen Indian timbers is reported.

\section{Experimental}

Samples of wood which were sun-dried and 2-3 years old were obtained with the help of the Divisional Forest Office, Warangal. Samples cut from the logs were used without oven-drying. However, after the experiment, small pieces were cut from the sample and subjected to oven-drying at $120^{\circ} \mathrm{C}$. From the mass of these pieces taken before and after oven-drying, it was found that the samples used in the experiments had a moisture content of $4-6 \%$.

The elastic properties of wood differ in directions parallel and perpendicular to the growth direction. Timber samples of meaningful size can be obtained only along the trunk length. Hence, only samples parallel to the trunk length were studied. Typical sample dimensions are $30 \times 2 \times 0.5 \mathrm{~cm}$. 
The dynamic elastic modulus was determined by measuring the natural frequency of vibration of the bars. The bar was clamped at one end and was set in vibration with an electromagnet. A strip of thin steel blade was glued on the timber bar to make it respond to the electromagnet. The frequency of vibration was determined with a Radart electronic flash lamp stroboscope coupled with a neon flash lamp. By adjusting the frequency of the flash lamp to produce a stationary image of the vibrating bar, the frequency could be measured with an accuracy of $\pm 0.16 \mathrm{c} / \mathrm{sec}$. The density was obtained from the mass of a small rectangular piece cut from the bar. The measurements were made over the frequency range $30-60 \mathrm{c} / \mathrm{sec}$. The dynamic Young's modulus was obtained from the relation (Timoshenko and Young 1959).

$E_{d}=\left(48 \pi^{2} P l^{4} f^{2}\right) /(1.875) 4 t^{2}, P=$ density; $l=$ vibration length; $f=$ frequency of vibration; $t=$ thickness of the bar.

The frequency was measured for several lengths and $E_{d}$ was calculated by a least squares treatment of $f^{2}$ and $l^{-4}$ values. The uncertainty in the $E_{d}$ value due to random errors was estimated by standard regression procedures. Typically, the uncertainty in $E_{d}$ is $2-5 \%$.

\section{Results and discussion}

The $E_{d}$ values obtained for eleven timber samples are given in table 1. For teak, values obtained on two specimens are given. These agree within limits of errors, showing internal consistency in the measurements. The values obtained for teak, bandar and rosewood agree reasonably with the values for these species reported by John and Lal (1964). However, the difference in value can exist between samples of different origin. For the remaining eight samples, this seems to be the first measurement.

Table 1. Dynamic modulus of elasticity $\left(E_{d}\right.$ in units of $10^{11}$ dynes $\left.\mathrm{cm}^{-2}\right)$ of timbers.

\begin{tabular}{|c|c|c|c|}
\hline \multirow{2}{*}{ Timber } & \multicolumn{2}{|c|}{ Present values } & \multirow{2}{*}{$\begin{array}{c}\begin{array}{c}\text { Values of } \\
\text { John and Lal }\end{array} \\
E_{d}\end{array}$} \\
\hline & $\begin{array}{c}\begin{array}{c}\text { Density } \\
\left(\mathrm{g}^{\mathrm{cm}} \mathrm{cm}^{-3}\right)\end{array} \\
\end{array}$ & $E_{d}$ & \\
\hline Teak (Tectona grandis) & 0.664 & $\begin{array}{l}1.05 \pm 0.06 \\
1.08 \pm 0.05\end{array}$ & $1.21 \pm 0.03$ \\
\hline Rosewood (Dalbagia latifolia) & 0.924 & $1.39 \pm 0.06$ & $1.26 \pm 0.02$ \\
\hline Bandar (Adina cordifolia) & 0.586 & $1.04 \pm 0.02$ & $1.18 \pm 0.03$ \\
\hline Tiruman (Anogeissus latifolia) & 0.768 & $1.02 \pm 0.05$ & \\
\hline Tani (Terminalia belerica) & 0.826 & $1.42 \pm 0.08$ & \\
\hline Tuniki (Diospyros melanoxylon) & 0.651 & $1.09 \pm 0.05$ & \\
\hline Battaganam (Stephegyne parvifolia) & 0.653 & $0.94 \pm 0.04$ & \\
\hline Kodisha (Cloistanthus collinus) & 0.861 & $1.30 \pm 0.05$ & \\
\hline Somi (Soymida febrifuga) & 1.046 & $1.79 \pm 0.11$ & \\
\hline Chilkadudi (Polyalthia cerasoides) & 0.615 & $1.20 \pm 0.04$ & \\
\hline Narayeppa (Hardwickia binata) & 0.554 & $0.85 \pm 0.04$ & \\
\hline
\end{tabular}




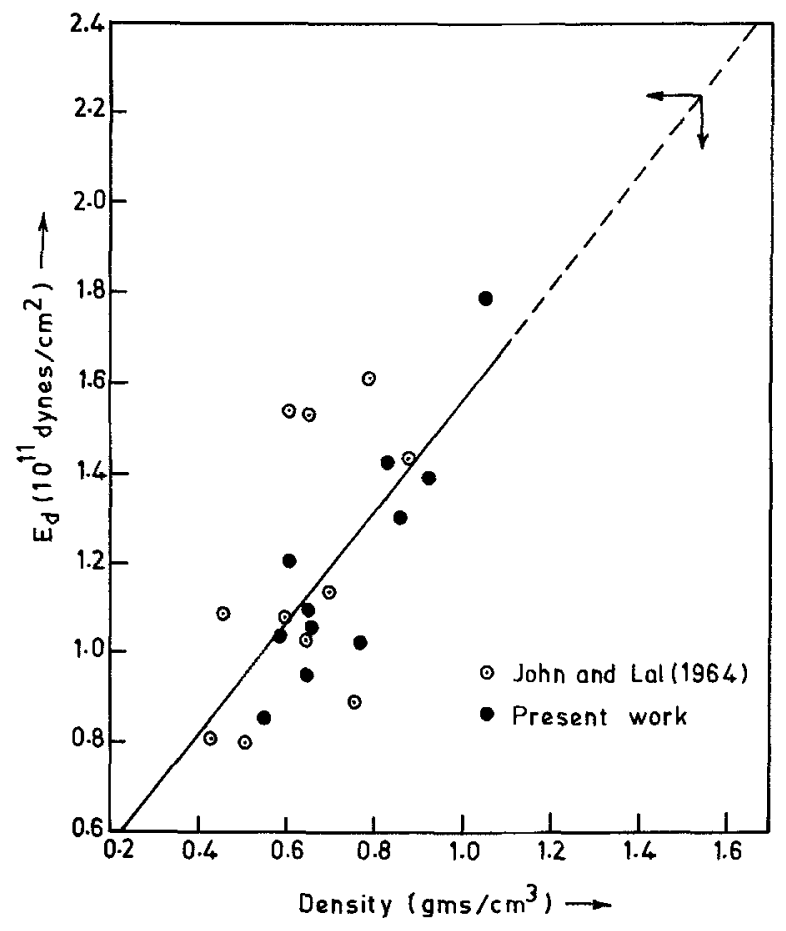

Figure 1. Plot of $E_{d}$ vs density of timbers.

The density of wood plays an important role in its physical behaviour. Bazhenov (1961) reported that the piezo-electric constants of timbers show a linear dependence on density. Hansen (1960) reported a nonlinear dependence of modulus of rupture on density of timbers. Merkulova (1961) observed that the elastic modulus of a given sample of wood increases with pressing of the sample (i.e. with increasing density). Bazhenov (1961) observed a linear dependence of the elastic modulus of oak, ash, aspen, beech, birch and pine on density.

So far, there is no analysis of data on the elastic modulus of Indian timbers - vis-a vis their densities. In figure 1 , the elastic modulus of timbers studied are plotted against density. The data obtained by John and Lal (1964) for,some timbers not studied in the present work, are also included in the figure. A near-linear relationship can be seen to exist between $E_{d}$ and the density.

Wood is composed of elongated cells connected with lignin. The actual wood substance has a density of $1.54 \mathrm{~g} \mathrm{~cm}^{-3}$. The effective density of a timber differs from this value, essentially because of its porosity and the variation in density from specimen to specimen arises out of the variation in the size and arrangement of cell cavities. Figure 1 therefore has an interesting significance. The linear plot, when extrapolated to a density of 1.54 , leads to an elastic modulus of about $2.2 \times 10^{11}$ dynes $\mathrm{cm}^{-2}$ (shown with arrows). This then is the upper bound for the Young's modulus of wood. If one could obtain perfectly seasoned, zero-porosity sample of any wood, its Young's modulus would be about $2.2 \times 10^{11}$ dynes $\mathrm{cm}^{-2}$. 


\section{References}

Bazhenov V A 1961 Piezoelectric properties of wood (New York: Consultants Bureau)

Hansen H J 1960 Modern timber design (London: John Wiley)

Hearmon R F S 1953 Mechanical properties of wood and paper (New York: Interscience Publ. Inc.)

John W J and Lal M M 1964 Indian J. Phys. 38401

Merkulova A I 1961 quoted by Bazhenov (see ref. above)

Pradhan B R 1970 Indian J. Pure Appl. Phys. 8486

Timoshenko S and Young D H 1959 Vibration problems in engineering (New York: Wan Nostrand Inc.) 